\title{
Perfil da aspartato aminotransferase e alanina aminotransferase e biometria do fígado de codornas japonesas
}

\author{
Anderson de Almeida Barbosa ${ }^{1}$, Elisa Sialino Müller ${ }^{1}$, George Henrique Kling de Moraes ${ }^{1}$, \\ Regina Tie Umigi ${ }^{2}$, Sergio Luiz de Toledo Barreto ${ }^{2}$, Ronaldo Martins Ferreira ${ }^{1}$
}

1 Departamento de Bioquímica e Biologia Molecular - UFV.
2 Departamento de Zootecnia - UFV.

RESUMO - Objetivou-se determinar o perfil da aspartato aminotransferase e alanina aminotransferase e a biometria do fígado de codornas poedeiras (Coturnix coturnix japonica) de 1 a 25 dias de idade. Avaliaram-se o peso vivo e o peso do fígado e as atividades das aspartato e alanina aminotransferases no fígado utilizando-se 90 codornas de 1 dia de idade. O delineamento experimental foi inteiramente casualizado com seis idades e cinco repetições, considerando cada animal uma unidade experimental. Aos 1, 5, 10, 15, 20 e 25 dias de idade, cinco animais foram sacrificados e os fígados coletados, pesados, congelados em nitrogênio líquido e armazenados a $-20{ }^{\circ} \mathrm{C}$. As alíquotas dos tecidos foram coletadas para determinação das atividades da aspartato e alanina aminotransferases no homogenato. O peso do fígado aumentou de acordo com a idade e não aumentou na mesma proporção que o peso corporal das codornas no mesmo período de crescimento. As atividades totais da aspartato aminotransferase e alanina aminotransferase apresentaram crescimento linear de acordo com a idade. A enzima aspartato aminotransferase apresentou maior atividade total em relação à alanina aminotransferase. No primeiro dia de vida, as enzimas já apresentaram atividades específicas consideráveis em relação às outras idades. A atividade da aspartato aminotransferase por grama de fígado foi bem maior que a da alanina em todas as idades. A atividade da enzima alanina aminotransferase por grama de peso corporal decresceu de forma linear com a idade. Os dados do perfil das das enzimas aspartato aminotransferase e alanina aminotransferase observados permitirão melhor ajuste dos níveis de proteína das rações para codornas.

Palavras-chave: metabolismo, perfil enzimático, transaminases

\section{Aspartate aminotransferase and alanine aminotransferase profile and biometry of Japanese quails liver}

\begin{abstract}
An experiment was conducted to determine the activities of aspartate aminotransferase and alanine aminotransferase and the liver biometry of laying quails (Coturnix coturnix japonica) from one to 25 days of age. Ninety, day-old, quails were used. A randomized complete experimental design was used with six ages, five replicates and one animal per experimental unit. At 1, 5, 10, 15, 20 and 25 days of age five animals were sacrificed, the liver removed, weighed, frozen with liquid nitrogen and stored at $-20{ }^{\circ} \mathrm{C}$. Liver samples were collected, homogenized and centrifuged to determine the homogenate aspartate aminotransferase and alanine aminotransferase activities. Liver weight developed linearly with age but differently from the body weight. Total aspartate aminotransferase and alanine aminotransferase activities showed a linear increase with age. Total aspartate aminotransferase showed higher activities than alanine aminotransferase. At one day old, quail liver aspartate aminotransferase and alanine aminotransferase had specific activities higher than those observed at other ages. Aspartate aminotransferase activity per g of liver was higher than aspartate aminotransferase at all ages studied. Alanine aminotransferase activity per g of body weight showed a linear reduction with age. The data observed will allow better adjustment of the level of protein in quail feed.
\end{abstract}

Key Words: enzymatic profile, metabolism, transaminases

\section{Introdução}

O fígado é um órgão central nos processos metabólicos e exerce múltiplas e importantes funções, centralizando a maior parte do processo homeostásico do organismo. Participa dos processos de digestão e de absorção intestinal por meio da síntese dos ácidos biliares e também possui relevante papel no metabolismo dos carboidratos, das proteínas e dos nucleotídeos, além de fundamentais funções na detoxicação de metabólitos. Nas aves apresenta-se normalmente sobrecarregado, pois não possuem sistema linfático plenamente desenvolvido. Assim, a gordura da 
dieta é totalmente levada ao fígado pelo sistema portahepático na forma de portomícrons. Além disso, é o único órgão responsável pela síntese de novo das gorduras de reserva provenientes do excesso de carboidratos da dieta.

Por ser um órgão atuante em diversas atividades metabólicas, a avaliação das atividades de enzimas de certas vias pode predizer seu status metabólico e sua habilidade de modificar suas atividades frente às diferentes alterações das condições do meio ambiente e das dietas. As transaminases hepáticas podem alterar suas atividades conforme a luminosidade do meio, o sexo dos animais (Toropila et al., 2005), o nível de aminoácidos não-essenciais (Guimarães et al., 1996), proteína (Truchlinski \& Grela, 1987) e gordura da dieta (Brooks \& Lampi 1995).

As transaminases (aminotransferases) correspondem a um importante grupo de enzimas que catalisam a transferência de um grupo amino de um aminoácido para um cetoácido. Alanina aminotransferase e aspartato aminotransferase são as transaminases mais importantes no diagnóstico clínico de diversas alterações metabólicas (Coles, 1974). Possuem ampla distribuição em tecidos, especialmente cérebro, coração, rim e fígado. Algumas transaminases são mitocondriais, algumas são citosólicas e outras em ambos os compartimentos celulares (Swenson \& Reece, 1996). No fígado, essas enzimas desempenham um importante papel no metabolismo de aminoácidos. Devido a sua importância, trabalhos têm sido realizados no intuito de quantificar a atividade dessas enzimas no fígado de frangos (Amubode \& Fetuga, 1984), porcos (Balogun \& Fetuga, 1980), ratos (Brooks \& Lampi, 1995) e em aves silvestres (Franson et al., 1985). Assim, objetivou-se determinar o perfil enzimático da alanina aminotransferase e da aspartato aminotransferase no fígado de codornas japonesas (Coturnix coturnix japonica) na fase de 1 a 25 dias.

\section{Material e Métodos}

O experimento foi realizado no Departamento de Zootecnia da Universidade Federal de Viçosa utilizando-se 90 codornas fêmeas (Coturnix coturnix japonica) com 1 dia de idade alojadas em boxes forrados com maravalha $(5 \mathrm{~cm})$. A temperatura foi mantida entre 33 e $36^{\circ} \mathrm{C}$ e suspensa aos 17 dias de idade. A água foi fornecida em bebedouro tipo copo de pressão e a ração em comedouro tipo bandeja.

As rações, compostas principalmente por milho e farelo de soja (Tabela 1), foram balanceadas segundo recomendações do NRC (1994).

O delineamento experimental foi inteiramente casualizado com seis idades e cinco repetições, conside- rando cada animal uma unidade experimental. Os modelos foram escolhidos com base na significância dos coeficientes de regressão (teste $\mathrm{t}$ com $5 \%$ de probabilidade), no coeficiente de determinação e no fenômeno biológico. Foi utilizado o programa Sistema para Análises Estatísticas e Genéticas-SAEG(UFV, 2000).

Ao atingirem 1, 5, 10, 15, 20 e 25 dias de idade, cinco aves foram sacrificadas. Os fígados foram pesados, congelados em nitrogênio líquido e armazenados a $-20{ }^{\circ} \mathrm{C}$. A uma alíquota de $100 \mathrm{mg}$ foram adicionados $10 \mathrm{~mL}$ de água destilada e deionizada gelada e o conteúdo homogeneizado (Homogeinizador, modelo TE-099, Tecnal). As amostras foram então centrifugadas a $7100 \times \mathrm{g}$ por 10 minutos e os sobrenadantes utilizados na determinação das atividades das enzimas aspartato e alanina aminotransferase e do teor de proteína solúvel total. As análises foram realizadas no Laboratório de Bioquímica Animal do Departamento de Bioquímica e Biologia Molecular da UFV.

Tabela 1 - Composição da dieta para codornas nas fases de cria e recria, em porcentagem da matéria natural

\begin{tabular}{|c|c|}
\hline & $\%$ \\
\hline Milho & 52,80 \\
\hline Farelo de soja (45\%) & 42,80 \\
\hline Fosfato bicálcico & 0,96 \\
\hline Calcário & 1,07 \\
\hline Óleo vegetal & 1,71 \\
\hline Sal & 0,26 \\
\hline DL-metionina (99\%) & 0,14 \\
\hline Avilamicina $^{1}$ & 0,01 \\
\hline Anticoccidiano $^{2}$ & 0,05 \\
\hline Suplemento mineral ${ }^{3}$ & 0,05 \\
\hline Suplemento vitamínico 4 & 0,10 \\
\hline Antioxidante 5 & 0,01 \\
\hline Total & 100,000 \\
\hline
\end{tabular}

Nutricional calculada

Proteína bruta $(\%)$

Energia metabolizável (kcal/kg) $2.900,00$

Cálcio (\%)

0,80

Fósforo disponível (\%) $\quad 0,35$

Sódio (\%) $\quad 0,15$

Lisina total (\%) 1,32

Lisina digestível (\%) 1,19

Metionina+cistina total (\%) $\quad 0,88$

Metionina+cistina digestível (\%) 0,79

Metionina total (\%) 0,51

Metionina digestível (\%) $\quad 0,47$

Triptofano total (\%) 0,31

Triptofano digestível (\%) $\quad 0,28$

Treonina total (\%) 0,94

Treonina digestível (\%) 0,82

${ }^{1}$ Surmax $^{\circledR}$.

${ }^{2}$ Coxistac $^{\circledR} 12 \%$.

${ }^{3}$ Composição/kg de produto: Mn - 160 g; Fe - 100 g; Zn - 100 g; Cu - 20 g; Co - 2 g;

I - 2 g; excipiente q.s.p. - 1.000 g.

${ }^{4}$ Composição/kg de produto: vit. A - 12.000 .000 UI; vit. $\mathrm{D}_{3}-3.600 .000 \mathrm{UI}$; vit. E - $3.500 \mathrm{UI}$; vit. $\mathrm{B}_{1}-2.500 \mathrm{mg}$; vit. $\mathrm{B}_{2}-8.000 \mathrm{mg}$; vit. $\mathrm{B}_{6}-5.000 \mathrm{mg}$; ácido pantotênico - $12.000 \mathrm{mg}$; biotina - $200 \mathrm{mg}$; vit. K - $3.000 \mathrm{mg}$; ácido fólico $1.500 \mathrm{mg}$; ácido nicotínico - $40.000 \mathrm{mg}$; vit. $\mathrm{B}_{12}-20.000 \mathrm{mg}$; Se - $150 \mathrm{mg}$; veículo q.s.p. - $1.000 \mathrm{~g}$.

5 Butil-hidróxi-tolueno. 
As atividades das transaminases foram determinadas utilizando-se kits. O método se baseia na propriedade dessas enzimas catalisarem a transferência do grupamento amino de um alfa-aminoácido para um alfa-cetoácido. Os produtos formados reagem com a dinitrofenilhidrazina formando hidrazona. A intensidade da coloração da hidrazona formada em meio alcalino é diretamente proporcional à quantidade de oxaloacetato e piruvato formado em determinado tempo, que por sua vez depende da atividade enzimática. A absorbância da mistura reacional foi medida a $505 \mathrm{~nm}$ e a intensidade da coloração formada foi proporcional à quantidade de produto formado e o zero foi ajustado com água destilada e deionizada. A quantificação de proteínas totais foi feita pelo método Lowry, que utiliza uma mistura contendo molibdato, tungstato e ácido fosfórico (reagente Folin-Ciocalteau). Esse reagente é reduzido quando reage com proteínas, na presença do cobre (II), e produz um composto com absorção máxima em 750 nm. Foi utilizada albumina sérica bovina (BSA) como padrão.

\section{Resultados e Discussão}

O peso dos órgãos internos tem sido sempre considerado na avaliação do desempenho dos animais. Nas aves, o fígado é considerado o mais relevante, pois centraliza o metabolismo geral, alterando seu peso e as atividades metabólicas. O fígado apresentou crescimento linear com a idade e não aumentou na mesma proporção que o peso corporal (Figura 1) no mesmo período de crescimento. Enquanto o peso corporal aumentou 13,71 vezes, o peso do fígado aumentou apenas 10,5 vezes no mesmo período.

Matsuzawa (1981) observou o mesmo comportamento para pesos corporal e de fígado em função da idade, em frangas. Contudo, rações à base de aminoácidos sintéticos podem alterar essas relações, principalmente o desenvolvimento do fígado (Batal \& Parsons, 2002), que apresenta menor peso absoluto em frangos alimentados com dietas compostas de milho e farelo de soja aos 7 e 21 dias de idade. Entretanto, a adição de parte dos aminoácidos na forma sintética parece não alterar o peso das vísceras. Stringhini et al. (2007) não encontraram diferenças no peso do fígado quando alteraram as relações lisina/arginina na dieta de frangos de corte. Da mesma forma, Oliveira Neto et al. (2007), trabalhando com vários níveis de metionina+cistina, também não encontraram diferenças significativas no peso do fígado.

Aumento linear do fígado em relação ao peso vivo foi observado ao longo de todo o período, comprovando crescimento adequado desse órgão em relação ao desenvolvimento do peso do animal (Figura 1). No entanto, os níveis de energia metabolizável (EM) da ração podem alterar o padrão de crescimento do fígado. Xavier et al. (2008) encontraram efeito linear positivo dos níveis de energia metabolizável da dieta sobre o crescimento do fígado em frangos da mesma idade. Esse perfil é importante, pois permite predizer, pela análise do peso de fígados, a presença de substâncias tóxicas na ração provenientes de fungos, como Aspergilus, que reduzem o desenvolvimento do órgão e o desempenho dos animais (Oliveira et al., 2004). O teor de proteínas solúveis totais no fígado utilizado nos cálculos das atividades específicas das enzimas aumentou de forma linear de acordo com a idade (Figura 1). O fígado, por ser um órgão central amplamente relacionado ao metabolismo de carboidrato, lipídios, proteínas e alterações em seu conteúdo proteico, pode revelar alterações de ordem metabólicas gerais. Rações com deficiência de vitamina $B_{6}$ podem
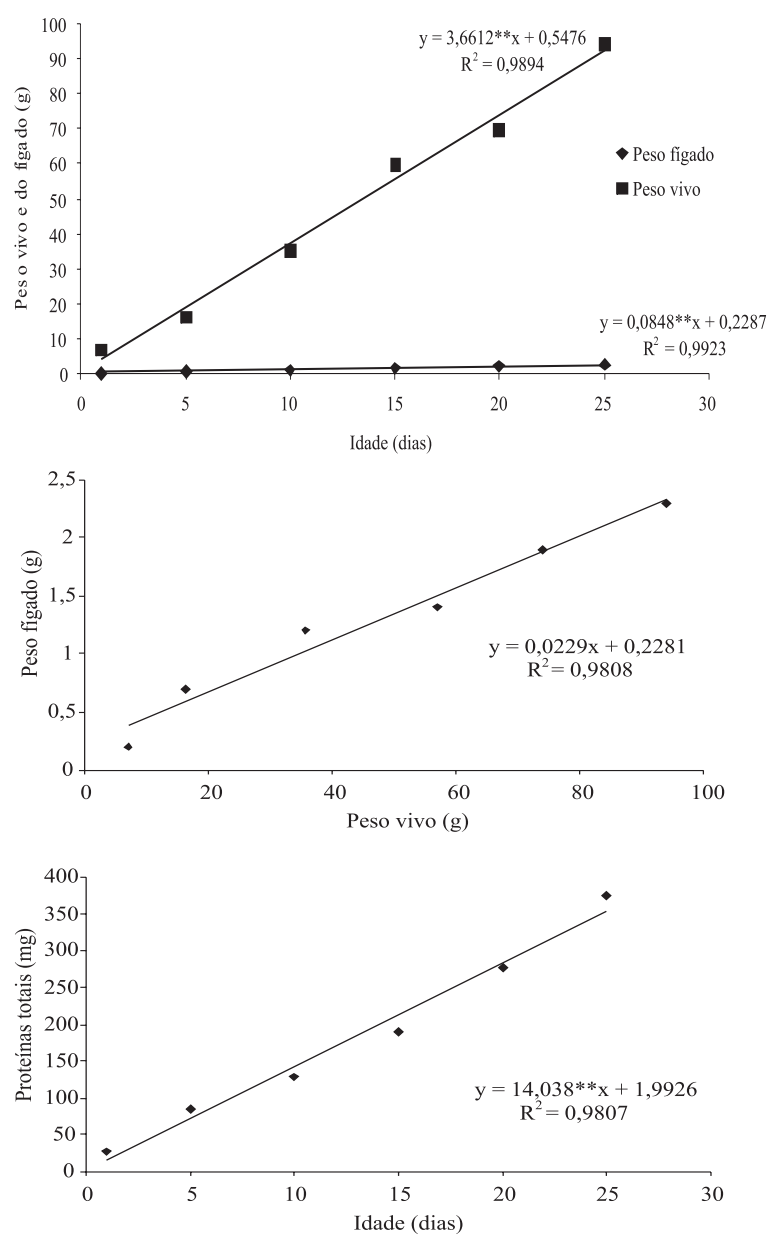

** significativo a $1 \%$ pelo teste $\mathrm{t}$.

Figura 1 - Estimativas do peso vivo e do fígado, da relação entre peso vivo e fígado (g) e quantidade (mg) de proteínas totais presentes no fígado. 
comprometer a atividade da aspartato aminotransferase, que é essencial na síntese de bases pirimidínicas como doador de grupos aminos. Isso pode comprometer todo o sistema de síntese, transcrição e tradução proteica, reduzindo tanto o tamanho do órgão como seus teores de proteína.

As atividades totais da aspartato aminotransferase e da alanina aminotransferase aumentaram de forma linear de acordo com a idade (Figura 2).

Já no primeiro dia de vida as codornas apresentavam atividades das enzimas aspartato aminotransferase e alanina aminotransferase, o que está de acordo com o observado por Telang \& Kothari (1975), que encontraram atividade da enzima aspartato aminotransferase em embriões de frango. Apesar de ambas terem apresentado aumento linear, a atividade hepática da aspartato aminotransferase foi maior que da alanina aminotransferase, o que estabelece uma diferença de aproximadamente cinco vezes, semelhante ao encontrado por Franson et al. (1985), que observaram que a atividade da enzima aspartato aminotransferase foi aproximadamente quatro vezes maior que a da enzima alanina aminotransferase no fígado de aves silvestres. Matsuzawa (1981) também observou que a atividade da enzima sérica da aspartato aminotransferase aumenta com a idade.

Nos oito primeiros dias de vida, a atividade específica da aspartato aminotransferase aumentou (Figura 2),
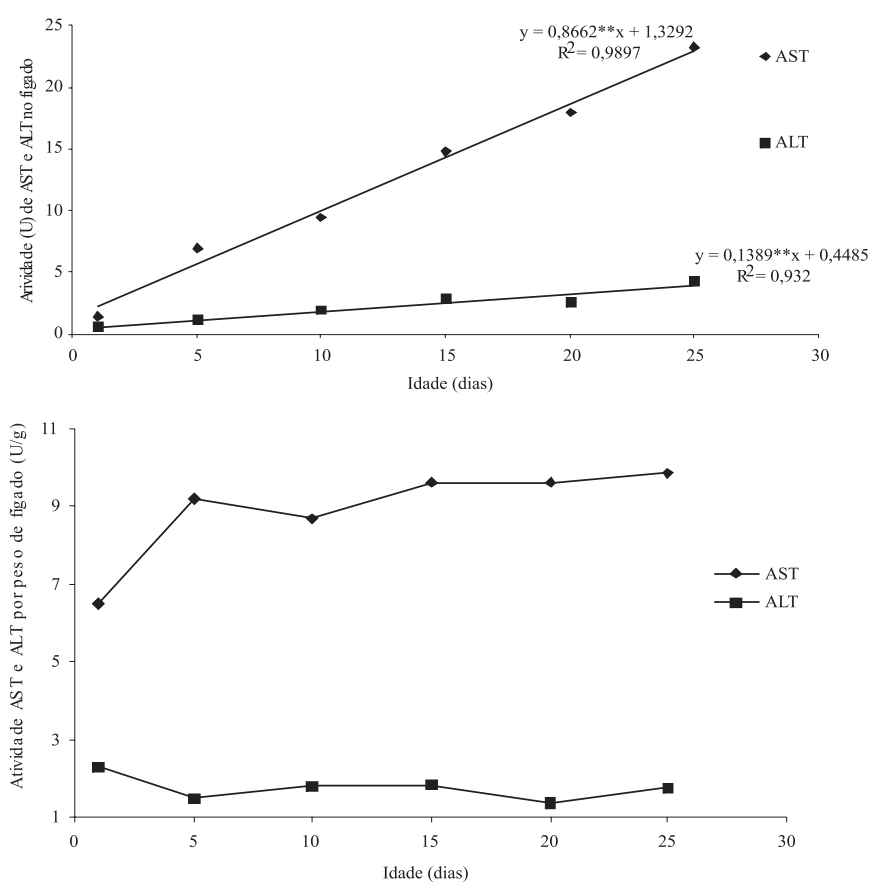

* significativo a $5 \%$ pelo teste $\mathrm{t}, * *$ significativo a $1 \%$ pelo teste $\mathrm{t},{ }^{* * *}$ significativo a $10 \%$ pelo teste $\mathrm{t}$.

Figura 2 - Atividade total e específica das enzimas aspartato e alanina aminotransferase no fígado de codornas japonesas. do pintinho quando começa a receber dieta com maior quantidade de carboidratos e proteínas em relação ao conteúdo do saco vitelínico, que é basicamente de lipídios. O aumento da atividade específica de aspartato aminotransferase é essencial para estabelecer as corretas relações dos aminoácidos para a síntese proteica no fígado, tendo em vista seu papel central na transferência de grupos aminos.

A presença de alimento no intestino delgado estimula a maturação dos enterócitos, assim como a maturação do pâncreas. Com o melhor aproveitamento da energia do alimento proveniente dos lipídios, a atividade específica diminui no fígado, pois, conforme descrito por Brooks \& Lampi (1995), o aumento de lipídios da dieta reduz a atividade, tanto de aspartato aminotransferase como de alanina aminotransferase no fígado, reduzindo sua atividade específica após o oitavo dia até atingir um valor aproximadamente estável aos 25 dias de vida dos animais.

A alanina aminotransferase parece estar mais envolvida nos níveis energéticos da dieta, assim, mostrou leve diminuição no padrão linear ao longo da idade à medida que ocorreu amadurecimento do aparelho digestório, disponibilizando melhor a energia do alimento. Isso está em conformidade com relatos de Amubode \& Fetuga (1984), que encontraram correlação negativa entre
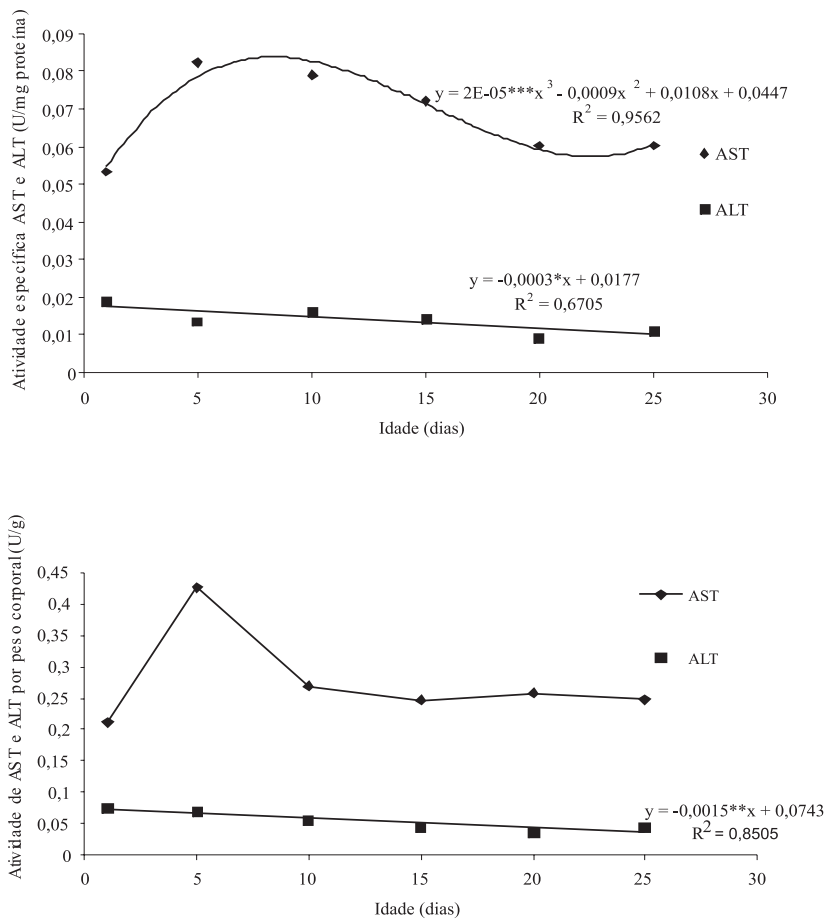
a atividade de aspartato aminotransferase e níveis de energia da dieta em frangos de corte.

Não houve modelo estatístico capaz de explicar os valores obtidos, mas a atividade de aspartato aminotransferase por grama de fígado foi bem maior que a da alanina aminotransferase em todas as idades (Figura 2), como observado por Franson et al. (1985) em duas espécies de patos silvestres. Nos cinco primeiros dias, a aspartato aminotransferase teve aumento de $41,69 \%$, enquanto a alanina aminotransferase teve diminuição de $65,05 \%$, mas, após esta idade, ambas mantiveram atividades proporcionais ao crescimento do fígado.

Não houve modelo estatístico que explicasse os valores obtidos para a atividade hepática da enzima aspartato aminotransferase em relação ao peso corporal ao longo da idade (Figura 2). Nos primeiros dias de vida, as aves passam por um processo de adaptação alimentar, uma vez que a dieta é rica em proteínas e carboidratos, assim, é possível que estes nutrientes tenham contribuído para o maior aumento da atividade dessa enzima aos 5 dias de idade. A partir dos 10 dias de idade, os valores se mantiveram na mesma faixa de atividade. A atividade da aspartato aminotransferase por grama de peso corporal apresentou decréscimo linear com a idade. Em decorrência dos baixos valores de atividade de alanina aminotransferase no fígado, torna-se difícil a associação com variações no peso vivo como forma de predição de alterações no desempenho animal (Cornelius, 1963).

\section{Conclusões}

A alanina aminotransferase tem comportamento mais uniforme em relação aos parâmetros comparados, portanto, pode ser de maior relevância para futuras análises de outras composições dietéticas. De acordo como os dados de biometria obtidos nas condições adotadas em rações compostas principalmente de milho e farelo de soja, o fígado é capaz de satisfazer as demandas metabólicas do animal.

\section{Agradecimentos}

\section{À FAPEMIG e ao CNPq, pelo apoio financeiro.}

\section{Referências}

AMUBODE, F.O.; FETUGA, B.L. The influence of dietary methionine, protein, and energy levels on glutamic-oxalacetate and glutamic-pyruvate transaminase of chicken. Beiträge zur Tropischen Landwirtschaft und Veterinärmedizin, v.22, n.1, p.193-200, 1984.
BALOGUN, O.O.; FETUGA, B.L. Liver glutamate-oxalate transaminase and glutamate-pyruvate transaminase activity in pigs as influenced by dietary methionine and lysine levels. Biochemistry and Experimental Biology, v.16, n.1, p.42-50, 1980.

BATAL, A.B.; PARSONS, C.M. Effects of age on development of digestive organs and performance of chicks fed a cornsoybean meal versus a crystalline amino acid diet. Poultry Science, v.81, p.1338-1341, 2002.

BROOKS, S.P.J.; LAMPI, B.L. The effect of changing dietary fat and carbohydrate on the enzymes of amino acid metabolism. Nutritional Biochemistry, v.6, p.414-421, 1995.

COLES, E.H. Liver function. Veterinary clinical pathology. 2.ed. Philadelphia: Saunders, 1974. 165p.

CORNELIUS, C.E. Relation of body-weight to hepatic glutamic pyruvic transaminase activity. Nature, v.200, p.580-581, 1963.

FRANSON, J.C.; MURRAY, H.C.; BUNCK, C. Enzyme activities in plasma, kidney, liver, and muscle of five avian species. Journal of Wildlife Diseases, v.21, n.1, p.33-39, 1985.

GUIMARÃES, V.M.; MORAES, G.H.K.; FONSECA, J.B. et al. Efeitos de aminoácidos não essenciais da dieta sobre glutamato-oxaloacetato transaminase hepática e composição química parcial de tíbias e fêmures de pintos de corte. Revista Brasileira de Zootecnia, v.25, n.3, p.481-493, 1996.

MATSUZAWA, T. Changes in blood components and organ weights in growing White Leghorn chicks. Growth, v.45, n.3, p.188-197, 1981.

NATIONAL RESEARCH COUNCIL - NRC. Nutrient requirements of poultry. 9.ed. Washington, D.C.: National Academy of Sciences, 1994. 155p.

OLIVEIRA NETO, A.R.; OLIVEIRA, R.F.M.; DONZELE, J.L. et al. Níveis de metionina + cistina total para frangos de corte de 22 a 42 dias de idade mantidos em ambiente termoneutro. Revista Brasielira de Zootecnia, v.36, n.5, p.1359-1364, 2007.

OLIVEIRA, C.A.F.; BUTKERAITIS, P.; ROSMANINHO, J.F. et al. Alterações hepáticas em codornas japonesas submetidas à intoxicação prolongada por aflatoxina $B_{1}$. Ciência Rural, v.34, n.1, p.213-217, 2004.

STRINGHINI, J.H.; CRUZ, C.P.; THON, M.S. et al. Níveis de arginina e lisina digestíveis na dieta de frangos de corte na fase pré-inicial. Revista Brasileira de Zootecnia, v.36, n.4, p.1083-1089, 2007.

SWENSON, M.J.; REECE, W.O. Fisiologia dos animais domésticos. 11.ed. Rio de Janeiro: Guanabara Koogan, 1996. $856 \mathrm{p}$.

TELANG, N.T.; KOTHARI, R.M. Aspartate aminotransferase activity during early development of chicken embryo. Differentiation, v.4, p.61-64, 1975.

TOROPILA, M.; NOVÁKOVÁ, J.; DANOVÁ, D. et al. Changes in the activity of selected adaptative enzymes in laboratory rats in relation to sex during prolonged fasting. Folia Veterinaria, v.49, n.3, p.48-50, 2005.

TRUCHLINSKI, J.; GRELA, E. Alanine and aspartate transaminase and acid and alkaline phosphatase activities in the blood serum in relation to the protein and energy levels in the pig's feeds. Polskie Archiwum Weterynaryjne, v.27, n.2, p.129-136, 1987.

UNIVERSIDADE FEDERAL DE VIÇOSA - UFV. SAEG Sistema de análises estatísticas e genéticas. Versão 8.0 . Viçosa, MG, 2000. Disponível em: <http://www.ufv.br> Acesso em: 30/1/2008.

XAVIER, S.A.G.; STRINGHINI, J.H.; BRITO, A.B. et al. Níveis de energia metabolizável em rações pré-iniciais para frangos de corte. Revista Brasileira de Zootecnia, v.37, n.1, p.109-115, 2008. 